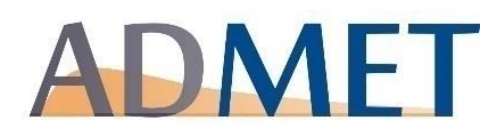

Open Access : ISSN : 1848-7718

Review

\title{
ROCK inhibitors in ocular disease
}

\author{
Éva Halász, Ellen Townes-Anderson*
}

Rutgers New Jersey Medical School, Department of Pharmacology, Physiology and Neuroscience, 185. S. Orange Ave, Newark, New Jersey, 07103

*Ellen Townes-Anderson: E-mail: andersel@njms.rutgers.edu ; Tel.: +1-973-972-7392; Fax: +1-973-972-5059

Received: July 29, 2016; Revised: November 30, 2016; Published: December 26, 2016

\begin{abstract}
Rho kinases (ROCKs) have a crucial role in actin-cytoskeletal reorganization and thus are involved in broad aspects of cell motility, from smooth muscle contraction to neurite outgrowth. The first marketed ROCK inhibitor, called fasudil, has been used safely for treatment of cerebral vasospasm since 1995 in Japan. During the succeeding decades ROCK inhibitors have been applied in many pathological conditions from central nervous system disorders to cardiovascular disease as potential therapeutic agents or experimental tools to help understand the underlying (patho)mechanisms. In 2014, a fasudil derivate named ripasudil was accepted for clinical use in glaucoma and ocular hypertension. Since ROCK kinases are widely expressed in ocular tissues, they have been implicated in the pathology of many ocular conditions such as corneal dysfunction, glaucoma, cataract, diabetic retinopathy, age-related macular degeneration, and retinal detachment. This paper aims to provide an overview of the most recent status/application of ROCK inhibitors in the field of eye disease.
\end{abstract}

\section{Keywords}

Rho kinase; corneal endothelial wound healing; glaucoma; diabetic retinopathy; retinal detachment

\section{Introduction}

In the past few years, ROCK inhibitors have undergone considerable structural, physico-chemical and pharmacokinetic development. A summary from last year listed more than 170 different compounds used in various research areas from cancer to respiratory disease [1], and since then the number of substances has only increased. In the case of ocular disease, ripasudil was approved in 2014 for the treatment of glaucoma and ocular hypertension (OHT) [2]. There are other promising candidates for ocular disease in phase II or phase III clinical trials; however, a number of drugs have also already failed [1,3] (see Table 1).

Most ROCK inhibitors target the ATP-binding site of the kinase in its active conformation and thereby reversibly compete with ATP [4]. The classic ROCK inhibitors are isoquinoline-derived fasudil or pyridinebased Y27632 or Y39983. Fasudil's specificity for ROCK was reported to be less than Y27632, however both compounds also inhibit other kinases including protein kinase $C$, protein kinase $A$, and myosin light chain kinase (MLCK) [5]. Because of these broader interactions, and especially in the case of in vivo studies using higher concentrations, it is not always possible to determine whether the results obtained are due to the on-target or the off-target effects. 
Table 1. Potential ROCK inhibitors for human ocular disease (N/A: not available).

\begin{tabular}{|c|c|c|c|c|}
\hline $\begin{array}{l}\text { Compound } \\
\text { Synonyms }\end{array}$ & Structure & $\begin{array}{c}\text { Company } \\
\text { IC50 values and [ref.] }\end{array}$ & Therapeutic application & Clinical trials \\
\hline \multirow{5}{*}{$\begin{array}{l}\text { Fasudil* } \\
\text { HA-1077 }\end{array}$} & & \multirow{5}{*}{ 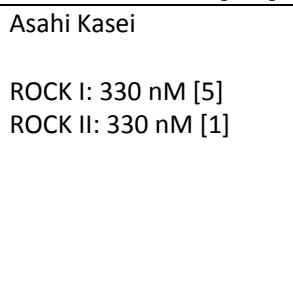 } & Cerebral vasospasm & Approved (China, Japan) \\
\hline & & & $\begin{array}{l}\text { Raynaud syndrome; } \\
\text { Scleroderma }\end{array}$ & Phase III (NCT00498615) \\
\hline & & & $\begin{array}{l}\text { Atherosclerosis } \\
\text { Hypercholesterolemia }\end{array}$ & $\begin{array}{l}\text { Phase II } \\
\text { (NCT00120718) }\end{array}$ \\
\hline & & & $\begin{array}{l}\text { Amyotrophic lateral } \\
\text { sclerosis }\end{array}$ & $\begin{array}{l}\text { Phase II } \\
\text { (NCT01935518) }\end{array}$ \\
\hline & & & Diabetic macular edema & Phase III (NCT01823081) \\
\hline \multirow{3}{*}{$\begin{array}{l}\text { Ripasudil* } \\
\text { K-115 }\end{array}$} & & \multirow{3}{*}{$\begin{array}{l}\text { Kowa Company } \\
\text { ROCK I: } 51 \mathrm{nM}[6] \\
\text { ROCK II: } 19 \mathrm{nM}[6]\end{array}$} & Glaucoma & Approved (Japan) \\
\hline & & & Diabetic retinopathy & $\begin{array}{l}\text { Phase II } \\
\text { (Japan, CTI:142456) }\end{array}$ \\
\hline & & & $\begin{array}{l}\text { Chronic obstructive } \\
\text { pulmonary disease }\end{array}$ & (NCT02219360) \\
\hline Y27632* & & $\begin{array}{l}\text { University of Kyoto } \\
\text { ROCK I: } 140 \mathrm{nM}[5] \\
\text { ROCK II: } 54 \mathrm{nM} \text { [8] }\end{array}$ & $\begin{array}{l}\text { Corneal endothelial } \\
\text { disorders }\end{array}$ & Phase I/II (Japan) \\
\hline $\begin{array}{l}\text { Y39983* } \\
\text { RKI-983, } \\
\text { SNJ-1656 }\end{array}$ & & $\begin{array}{l}\text { Senju/Novartis } \\
\text { ROCK I: N/A } \\
\text { ROCK II: } 3.6 \text { nM }[1,8]\end{array}$ & Glaucoma & Phase II (discontinued) \\
\hline $\begin{array}{l}\text { AR13324 } \\
\text { Rhopressa }\end{array}$ & & $\begin{array}{l}\text { Aerie Pharmaceuticals } \\
\text { ROCK I-II: N/A }\end{array}$ & Glaucoma & Phase III \\
\hline $\begin{array}{l}\text { PG324 } \\
\text { Roclatan } \\
\text { (AR13324+ } \\
\text { latanoprost) } \\
\end{array}$ & N/A & $\begin{array}{l}\text { Aerie Pharmaceuticals } \\
\text { ROCK I-II: N/A }\end{array}$ & Glaucoma & Phase III \\
\hline AR12286* & & $\begin{array}{l}\text { Aerie Pharmaceuticals } \\
\text { ROCK I-II:N/A }\end{array}$ & Glaucoma & Phase II (discontinued) \\
\hline $\begin{array}{l}\text { PG286 } \\
\text { (AR12286+ } \\
\text { travoprost) }\end{array}$ & $\mathrm{N} / \mathrm{A}$ & $\begin{array}{l}\text { Aerie Pharmaceuticals } \\
\text { ROCK I-II: N/A }\end{array}$ & Glaucoma & (Discontinued) \\
\hline AR13154* & N/A & $\begin{array}{l}\text { Aerie Pharmaceuticals } \\
\text { ROCK I-II:N/A }\end{array}$ & $\begin{array}{l}\text { Choroidea } \\
\text { neovascularisation }\end{array}$ & Animal model \\
\hline AMA0076 & Structure not disclosed & $\begin{array}{l}\text { Amakem } \\
\text { ROCK I: } 3.7 \mathrm{nM}[8] \\
\text { ROCK II: } 2.3 \mathrm{nM}[8]\end{array}$ & Glaucoma & Phase II \\
\hline AMA0428* & Structure not disclosed & $\begin{array}{l}\text { Amakem } \\
\text { ROCK I-II:N/A }\end{array}$ & AMD & Animal model \\
\hline ATS907 & & $\begin{array}{l}\text { Altheos } \\
\text { ROCK I: } 36 \mathrm{nM} \mathrm{[1]} \\
\text { ROCK II: } 37 \mathrm{nM}[1]\end{array}$ & Glaucoma & Phase II (discontinued) \\
\hline INS117548 & $\mathrm{N} / \mathrm{A}$ & $\begin{array}{l}\text { Inspire /Merck } \\
\text { ROCK I: } 5 \mathrm{nM} \mathrm{[1]} \\
\text { ROCK II: } 14 \mathrm{nM} \mathrm{[1]}\end{array}$ & Glaucoma & Phase I (discontinued) \\
\hline DE104 & N/A & $\begin{array}{l}\text { Santen } \\
\text { ROCK I-II:N/A }\end{array}$ & Glaucoma & Phase II (discontinued) \\
\hline \multirow[t]{3}{*}{ KD025* } & & \multirow{3}{*}{$\begin{array}{l}\text { Kadmon } \\
\text { ROCK I: >10 } \mu \mathrm{M} \text { [12] } \\
\text { ROCK II: } 59 \mathrm{nM} \text { [12] }\end{array}$} & Psoriasis & Phase II (NCT02106195) \\
\hline & & & $\begin{array}{l}\text { Idiopathic pulmonary } \\
\text { fibrosis }\end{array}$ & Phase II (NCT02688647) \\
\hline & & & $\begin{array}{l}\text { Graft versus host disease } \\
\text { (GVHD) }\end{array}$ & Phase II (NCT02841995) \\
\hline
\end{tabular}

*These drugs are still being used for in vitro or animal research 
Small modifications in structure lead to remarkable changes. For example, the fasudil derivative ripasudil at $50 \%$ of its effective concentration against ROCK I in cell free assays (IC50(Ki) $=0.051 \mu \mathrm{M}$ ) [6] has at least a 2-6 times higher binding affinity than that of other ROCK inhibitors such as Y27632 (IC 50(Ki) $=0.14$ $\mu \mathrm{M})$ or fasudil (IC $50(\mathrm{Ki})=0.33 \mu \mathrm{M})[5]$ at the same effective concentration. AMA0076 and Y39983 are both structurally related to Y27632 [7]. In in vitro assays, AMA0076 (IC50=2.3+/-0.9 nM) and Y39983 (IC50=4.3+/-2.1 nM) showed similar on-target potency for ROCK II, but they were at least ten times more potent than $\mathrm{Y} 27632$ (IC50=54+/-23 nM). In normotensive rabbits AMA0076 also was slightly more effective in reducing the fluid-based pressure of the eyeball, a measure used to diagnose glaucoma and called the intraocular pressure (IOP), than Y39983 [8].

Stability in solution can also be disparate. Both fasudil and Y27632 were effective at reducing IOP in animal models [6], however the stability of the solutions was poor $[9,10]$. The Y27632-derivative Y39983 was stabile in solution and shown to have 30 times more ROCK inhibition and to be 10 fold more effective at lowering IOP than Y27632 in animal models [9]. Nonetheless, clinical trials with Y39983 were discontinued after phase II, probably because of treatment-related side effects [11]. Fasudil-derived ripasudil proved to be safe and stabile for topical instillation and, as noted, has been approved for treatment of glaucoma [2].

One important direction for future ROCK inhibition development is the development of ROCK I and ROCK II specific drugs. KD025 is an orally available, potent and highly selective small molecule ROCK II inhibitor (IC 50= 60 nM/L) [12], developed by Kadmon Company and currently in phase II clinical trials for chronic pulmonary fibrotic and systemic autoimmune disease (ClinicalTrials.gov: NCT02106195; NCT02688647).

Bi- or tri-functional small molecule inhibitors are also being developed. These drugs usually are comprised of a ROCK inhibitor and one or more drugs with additional therapeutically relevant targets. For example, rhopressa, a bi-functional drug, is made up of a ROCK inhibitor and a norepinephrine transporter inhibitor [13], and roclatan, a tri-functional drug, is made up of a fixed combination of rhopressa with latanoprost [14]. Both of them were developed by Aerie Pharmaceuticals and are in phase III clinical trials [15].

A drug approach with less side effects has been developed by the Amakem company for localized applications of ROCK inhibitors. In this approach, the drug is active where it is applied but once the drug enters the systemic circulation, the compounds are metabolized into non-toxic inactive metabolites through the activity of an esterase. These drugs are known as soft drugs. Adding (and modifying) ester moieties to an otherwise classical ROCK inhibitor results in variability in drug stability, with plasma half-life times from less than 5 minutes to more than 120 minutes [7]. AMA0076 lowered intraocular pressure in New Zealand white rabbits with minimal hyperemia, and was more efficient than Y39983 at the same concentration [8]. This soft drug was in phase II clinical trials in 2014, however results from the trials have not yet been disclosed. Another soft ROCK inhibitor, AMA0428, has been shown to not only reduce neoangiogenesis but also to block inflammation and fibrosis in an animal model of neovascular age-related macular degeneration (AMD) [16].

\section{ROCK and the Rho signaling pathway}

ROCKs (also called coiled-coil containing protein kinases) are small $160 \mathrm{kDa}$ serine/threonine kinases. They were first described as RhoA-GTP interacting proteins [17]. Two isoforms of ROCK have been identified: ROCK I and ROCK II. In humans the two isoforms share more than $60 \%$ identity in their amino 
acid sequence and around $90 \%$ homology of their kinase domain $[18,19]$. Structurally ROCKs are composed of the following major parts: a kinase domain at the $\mathrm{N}$ terminal, which phosphorylates the protein targets, a Rho-binding domain (RBD), where the upstream activator binds, and the C-terminal, which contains a pleckstrin homology (PH) and cysteine rich domain (CRD). Rho A, Rho B and Rho $C$ are isoforms, small GTPases of the Rho family, and are usually collectively known as Rho [17]. ROCKs can be activated by the GTP-bound form of Rho. Binding of Rho-GTP opens the loop formation of the enzyme, and the activated form then phosphorylates downstream targets [17] (Figure 1). Among other substrates, ROCK directly phosphorylates myosin light chain (MLC) and the myosin binding subunit of myosin light chain phosphatase, thereby enhancing actin-myosin-mediated contractility and promoting formation of stress fibers and focal adhesions [20-22]. LIM kinases are also downstream targets of ROCK, and these kinases have a pivotal role in cofilin-mediated actin filament disassembly. Cofilin binds to actin and enhances actin depolymerization, whereas activated LIM kinases phosphorylate the cofilin and inhibit its filament binding activity [23]. ROCKs also phosphorylate other actin binding proteins, for instance adducin, which interacts with spectrin-actinnetworks and ERM (ezrin-radixin-moesin) proteins which are cross linkers between actin filaments and membrane proteins $[17,24]$. Taken together, Rho pathway activation leads to a concerted series of events resulting in increased actin-myosin contractility and cytoskeletal change.

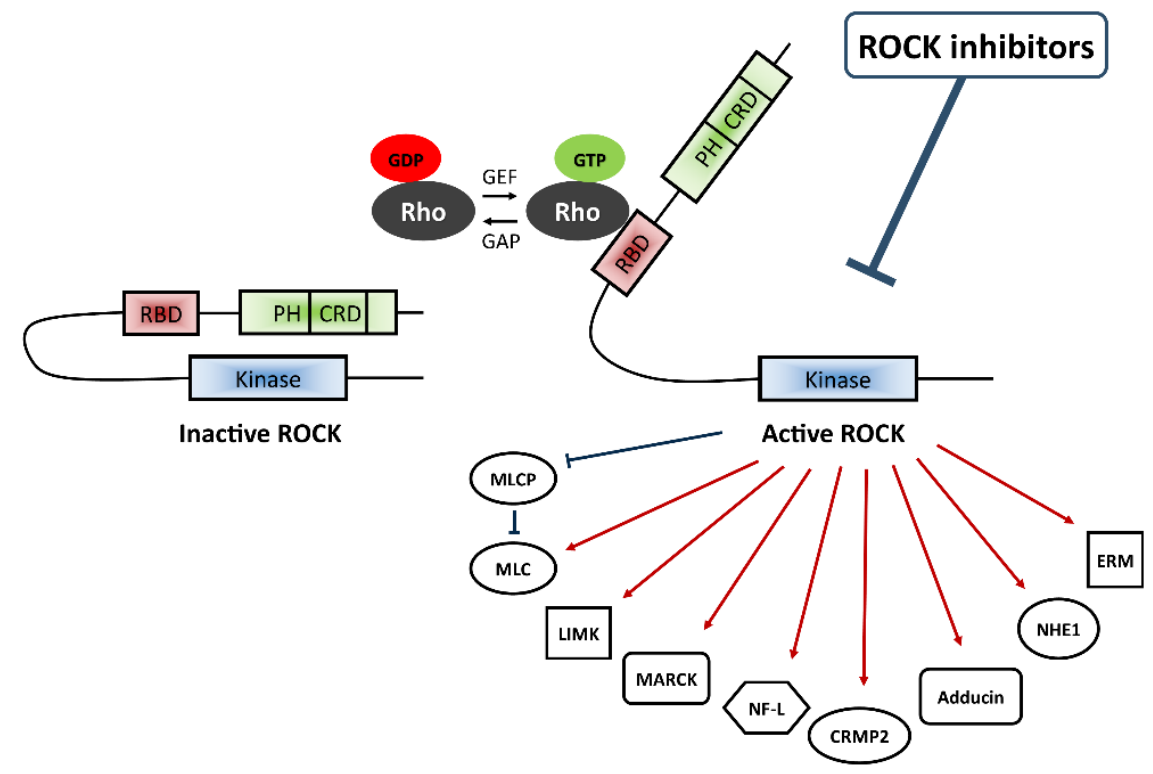

Figure 1 . Regulation of Rho kinase (ROCK) and downstream effectors.

(RBD: Rho-binding domain, PH: pleckstrin homology domain, CRB: cysteine-rich region domain, GEF: Guaninenucleotide exchange factor, GAP: GTPase activating proteins, GDP: guanosine diphosphate, GTP: guanosine triphosphate, MLCP: myosin light chain phosphatase, MLC: myosin light chain, LIMK: LIM kinases, MARCK: Myristoylated alanine-rich C kinase substrate, NF-L: neurofilament L protein, CRMP2: Collapsin response mediator protein-2, NHE-1: sodium/hydrogen exchanger-1, ERM: ezrin-radixin-moesin)

Genetic deletion of ROCK I and II in mice helped explore specific functions of ROCK I and ROCK II (during development). Homozygous ROCK I -/-mice were born in the expected Mendelian ratio, however they had a developmental defect in eyelid and ventral body closure, resulting in different degrees of eye opening at birth (EOB) and omphalocele [25]. In contrast, for ROCK II -/- mice, approximately $90 \%$ of the embryos died in utero. The newborns that did survive were runts, albeit subsequently fertile without particular anatomical abnormality [26]. Double ROCK I +/- and ROCK II +/- heterozygous mice were also born with open eyelids and incomplete ventral body closure [27]. Histological examination revealed impaired formation of actomyosin cables, demonstrating that both kinases promote actin bundling in vivo. However, the results suggest that the function of two enzymes are not $100 \%$ identical; in these systems, the isoforms 
do not compensate for the loss of each other. Both ROCK isomers are present in ocular tissues [28] and aberrant regulation of ROCK levels plays a role in the pathogenesis of glaucoma, diabetic retinopathy, and $A M D$, to mention the most frequently investigated areas.

\section{Corneal Wound Healing}

Corneal endothelial cells are the innermost layer of the cornea and have a crucial role in maintaining cornea transparency. In late adulthood, the cell density of the healthy cornea endothelium is approximately 2500 cells $/ \mathrm{mm}^{2}$, however if for some reason density falls under the critical level of $500 \mathrm{cells} / \mathrm{mm}^{2}$ compensatory changes begin and the cornea exhibits edema and haziness, notably decreasing visual acuity. Typical reasons for endothelial cell loss can be trauma caused by cataract surgery, pseudophakic bullous keratopathy and Fuchs endothelial dystrophy. Since human endothelial cells have poor in vivo proliferative potency, these conditions lead to compensatory enlargement of the remaining endothelial cells and corneal endothelial dysfunction. Long term, chronic inflammation and cytokine imbalance can also cause corneal neovascularization, which affects different layers of the cornea. At present definitive clinical therapy for effective treatment of corneal endothelial dysfunction has not been developed. In advanced phases, corneal transplantation can be performed, however several problems can arise associated with the operation including primary graft failure, graft rejection or inflammation. However, in the past few years ROCK inhibitors have been investigated to elucidate their role and potential applicability as treatment of corneal endothelial disorders.

Intriguing recent findings suggest that ROCK inhibitors have a beneficial effect in corneal wound healing. In 2009, Okumara et al. [29] showed that different concentrations of Y27632 (1, 10, 33, $100 \mu \mathrm{M})$ enhanced the survival of monkey corneal endothelial cells, however, only the $10 \mu \mathrm{M}$ concentration resulted in a significant increase in cell survival. These in vitro studies indicated that the optimal concentration of Y27632 also promoted cell adhesion and increased proliferative capacity [29]. Based on these findings, in vivo studies using topically administered Y27632 were performed. In a primate endothelial injury model, artificially injured eyes were treated with $10 \mathrm{mM}$ Y 27632 using eye drops, six times a day. After two days the difference between the treated and the non-treated eye in the size of the wound was remarkable. Furthermore, after one week non-contact specular microscopy showed normal cell morphology and cell density (of $3000 \mathrm{cell} / \mathrm{mm}^{2}$ ) in the treated group, in contrast with the control group, where the examined area exhibited enlarged corneal endothelial cells (CEC) and a cell density of only 1500 cells $/ \mathrm{mm}^{2}$ [30].

Descemet's membrane is the basement membrane of the corneal endothelium. It can detach spontaneously, or be removed during cataract surgery, or other injuries. The importance of an intact Descemet's membrane in corneal endothelial recovery has been investigated in in vitro studies [31,32]. In a rabbit organ culture model (treated with $10 \mu \mathrm{M}$ Y 27632 for 48 hours) there was no difference between the presence and absence of Descemet's membrane, and the ROCK inhibitor increased CEC proliferation to approximately the same level in both samples [31]. In contrast, in human CEC culture (treated with $10 \mu \mathrm{M}$ Y27632 for 14 days), results suggest that the presence of an intact Descemet's membrane does affect corneal endothelial wound healing [32]. Soh et al. [32] observed that the maximum endothelial recovery in culture without Descemet's membrane was around $20 \%$, whereas with intact Descemet's membrane recovery was approximately $80 \%$ due to increased endothelial migration. These differing results may be due to species differences or differences in the experimental models. For instance, in the case of the rabbit organ culture the epithelium was also removed, thus enhancing the access of the drug to the corneal endothelium.

Another approach to the treatment of corneal endothelial disorders is injection of cultured allogeneic 
corneal endothelial cells (CECS) into the anterior chamber. Intracameral injection of CECs followed by facedown positioning for 3 hours was performed with or without supplementation of a ROCK inhibitor (Y27632) in rabbit and monkey corneas with the endothelium removed but an intact Descemet's membrane. In the rabbit, intracameral injection of CECs with $100 \mu \mathrm{M}$ Y27632 (for 2 weeks) helped in the recovery of corneal transparency and decreased edema. The central corneal thickness in the Y27632 supplemented group was $<800 \mu \mathrm{m}$, whereas without drug it was $>1200 \mu \mathrm{m}$ during the 2 -week period. In the monkey model 3 months after allogeneic transplantation of CECs, the cell density in the drug supported group was 3 times higher compared to the "pure" CEC-injected group. In both animal models, reconstructed endothelium with Y27632 treatment exhibited monolayer hexagonal cell shapes with normal expression of functionallyrelated endothelial markers. In contrast, in the absence of ROCK inhibitor, cells showed a stratified fibroblastic phenotype, and reduced levels of endothelial functional markers [33]. In a feline model of endothelial dysfunction, Bostan et al. examined the contribution of injected CECs to the new endothelium and whether repair with ROCK inhibition worked through increased adherence of the injected cells, stimulation of CEC migration to the injured area, or both. Surprisingly, the best endothelial recovery occurred in a scenario where Y27632 was injected without CECs and with limited endothelial scraping allowing the host to provide sufficient peripheral endothelial cells to migrate towards and cover the wound [34].

Y27632 has not yet been approved for human application. A phase 1 clinical trial was performed in Japan involving 10 healthy volunteers. This study confirmed that Y27632, applied as $10 \mathrm{mM}$ eye drops 6 times daily for 7 days, did not cause any systemic or local side effects [30]. Eight patients who suffered from corneal deficiency were subsequently enrolled to test the feasibility of the drug in pathological conditions. After 6 months, Y27632-treated participants with central corneal edema showed slight reductions in the central corneal thickness; however, for those patients with diffuse edema there was no difference between the pre- and post-treatment thickness. Among the 8 patients, there were a few cases where the best corrected visual acuity also improved, but for most, vision remained the same [30]. A case report of lateonset Fuchs corneal dystrophy of a 52-year-old patient who received $10 \mathrm{mM} \mathrm{Y27632} \mathrm{topically} \mathrm{six} \mathrm{times} \mathrm{daily}$ for one week showed recovered corneal clarity and improved visual acuity after two weeks. These positive changes were maintained up to the final examination, two years later in this case [35]. Last, but not least, in 2015, Okumara et al. [31] reported on 3 patients who had severe corneal endothelial damage due to cataract surgery and received Y27632 eye drops. Two of them received $1 \mathrm{mM} \mathrm{Y27632}$ eye drops administered 6 times daily in the first 4 months, and 4 times daily during the following 2 months; the third patient used the drug four times daily only for 3 months. The first two patients had spontaneous detachment of Descemet's membrane during surgery, which could have further impaired the healing of the wound. However, in contrast with the in vitro findings [32], in these cases the corneal endothelium was reconstructed on bare corneal stroma and the corneal clarity recovered. When the first patient was referred to the cornea clinic she was only able to count fingers with her right eye. By three months, her vision was 20/20. The third patient had an intact Descemet membrane but the corneal endothelial cell density was critically low (508 cells $/ \mathrm{mm}^{2}$ ). Contrary to expectations, by the third month, the cornea became clear and the visual acuity increased from the initial 20/63 to 20/25 [31]. Although these human studies have a number of limitations, for example patients without treatment were not followed and the results are very preliminary, taken together they suggest that ROCK inhibitors may be effective in reducing corneal edema, and/or improve wound healing.

Another ROCK inhibitor, Y39983, has been applied to in vitro and in vivo corneal endothelial wound healing models and seems to be more effective for corneal endothelial cell proliferation than Y27632. 
According to results in human endothelial cell culture, Y39983 increased the percentage of proliferating cells in a dose dependent manner; application of $3 \mu \mathrm{M}$ Y39983 achieved a significant increase compared to the control group. In addition, in monkey corneal endothelial cell culture administration of only 0.3 or $3 \mu \mathrm{M}$ Y39983 resulted in the same level of CEC proliferation that was achieved with $10 \mu \mathrm{M}$ Y27632. Topical administration of $0.095 \mathrm{mM}$ Y39983 six times daily for two days in a rabbit model significantly decreased the size of the corneal endothelial wound and increased corneal endothelial cell proliferation compared to the non-treated control group [36].

Given the recently reported promising outcomes with ROCK inhibitors in glaucoma (see the next section), Okumara et al. [37] examined the applicability of ripasudil eye drops as a potential therapeutic agent in corneal endothelial injuries. In human CEC cultures all concentrations of ripasudil $(0.3,1,3,10,30$ $\mu \mathrm{M}$ ) enhanced the proliferative potential of the corneal endothelium at least the same or more effectively than $10 \mu \mathrm{M}$ Y27632 or $10 \mu \mathrm{M}$ fasudil. In an in vivo model of corneal wounding, rabbits received $0.4 \%$ ripasudil eye drops three times daily for two weeks; five of six ripasudil-treated corneas became transparent again and the central corneal thickness decreased to a normal value, whereas the control corneas did not change. Moreover, the corneal endothelial cell-density and the expression of pump function-related markers were higher in the ripasudil-treated animals compared to the vehicle-treated group. According to their findings, proliferating cells were not observed after the injured area was fully covered by CECS, which indicates that ROCK inhibitors do not induce cell proliferation after the endothelium is successfully reconstructed [37].

In light of the fact that the cornea is normally avascular, it can be a useful organ in the evaluation of angiogenesis. In an in vivo mouse model, it has been reported that fasudil can inhibit VEGF-induced corneal neovascularization without adverse effects such as corneal edema or inflammation. However, in this experimental model the concentration of the effective dose in the cornea could not be measured precisely, because they administered the drug in the form of Hydron pellets [38]. In live rabbits, alkali-burn-induced corneal fibrosis and neovascularization were also significantly reduced by fasudil ( $50 \mu \mathrm{L}, 3 \mathrm{nM}$ ) applied topically twice daily for three days (corneas were harvested after two weeks) compared to the basic salinetreated control group. The histological examination confirmed the initial biomicroscopical findings: the fasudil-treated corneas exhibited significantly less staining for fibrotic markers (smooth muscle actin, fibronectin, F-actin) than the control group [39]. Zeng et al. [40] also demonstrated that ROCK inhibitors (fasudil) can promote the healing of corneal epithelial defects and inhibit the formation of neovascularization. In their alkali burn mouse cornea model they used different concentrations of fasudil (30, 100, 300, $1000 \mu \mathrm{M}$ eye drops, applied 4 times daily, for 14 days). Although only the $100 \mu \mathrm{M}$ dose inhibited the corneal neovascularization significantly at all time points examined compared to the control group, corneal re-epithelization was significantly accelerated by 100,300 , and $1000 \mu \mathrm{M}$ of fasudil.

According to current understanding, inflammation and reactive oxygen species (ROS) contribute, at least in part, to neo-angiogenesis. In an in vivo corneal neovascularization murine model, $100 \mu \mathrm{M}$ topical fasudil appeared to serve as a potential antioxidant because there was decreased ROS activity, as well as reduced expression of angiogenesis related genes (VEGF, TNF-alfa, MMP-8, MMP-9) and increased levels of protective heme oxygenase 1 (HO-1). In addition, the number of inflammatory cells in the cornea was reduced [40].

Thus, ROCK inhibition has been shown to have effects on corneal endothelial migration and proliferation and on corneal neovascularization. 


\section{Glaucoma}

Glaucoma is a progressive optic neuropathy characterized by ganglion cell death which leads to concomitant thinning of the retinal nerve fiber layer and visual field loss. In spite of the fact that glaucoma is the leading cause of irreversible blindness worldwide, the etiology of the disease is still not fully understood. Present clinical therapeutic strategies focus on lowering intraocular pressure (IOP) via pharmacologic agents or surgical procedures. ROCK inhibitors may have potential in glaucoma therapy in at least three ways: lowering the intraocular pressure, reducing the scarring after filtration surgery, and neuroprotection (neuroprotection is discussed in the Retina section).

Proposed IOP lowering mechanism: The cause of elevated IOP levels originates from the imbalance between production of aqueous humor and drainage of aqueous humor. The aqueous humor is traditionally considered to drain out of the eye through either the conventional pathway via the trabecular meshwork (TM) or the unconventional pathway via the uveoscleral route. Normally, the TM is a spongy connective tissue containing collagen and elastin fibers surrounded by trabecular cells, which display smooth-muscle like properties such as actin-myosin contractility. Contraction of TM cells or ciliary muscle results in reduced aqueous humor outflow and increases the IOP. Activated ROCK takes part in regulation of ciliary muscle and trabecular meshwork cell contraction through phosphorylation of the myosin binding subunit of myosin light chain phosphatase [28] and direct phosphorylation of myosin light chain [41]. As previously described, LIM kinases are downstream targets of ROCK, and their activation leads to stabilization of actin polymerization by phosphorylated cofilin. LIMK inhibition (either directly or through a ROCK inhibitor) is considered to induce trabecular meshwork relaxation via depolymerization of actin filaments [42].

Aqueous humor in patients with primary open angle glaucoma contains elevated levels of endothelin 1 (ET-1) [43] and tissue growth factor- $\beta$ (TGF- $\beta$ ) [44] which are upstream activators of the Rho-ROCK pathway $[3,45]$. ROCK inhibitors have been shown to act directly on primate TM and Schlemm's canal (SC), lowering the IOP by increasing the outflow of the aqueous humor through the conventional pathway. In normotensive monkeys, AR13324 increased the outflow facility by $53 \%$ and reduced the IOP by more than $20 \%$ compared to the contralateral vehicle-treated eye [46]. Primate trabecular meshwork cells treated with different ROCK inhibitors (Y27632, fasudil, ripasudil) exhibited rounding and a decreased number of actin bundles. These changes returned two hours after drug removal. All three of these ROCK inhibitors enhanced Schlemm's canal endothelial cell permeability probably via tight junction disruption [6]. In human TM and SC cell culture, Y27632 caused reversible changes in cell shape, decreased the presence of actin stress fibers and focal adhesions, and significantly increased the Schlemm's canal monolayer permeability (Figure 2).

The IOP lowering effect of different ROCK inhibitors has been examined in many other in vivo and in vitro animal models. In rabbits, a single instillation of $0.4 \%$ ripasudil doubled the conventional outflow facility, although there was no effect on the uveoscleral route [47]. Enucleated porcine eyes perfused with Y27632 (10, 50, $100 \mu \mathrm{M})$ showed in a significant increase in aqueous humor outflow facility, and structurally the entire TM appeared to be distended and exhibited widening of extracellular spaces [41]. Using optical coherence tomography in the living mouse, the real-time drug effects on TM and Schlemm's canal were observed. Li at al. [48] reported that topically applied ROCK inhibitor (AR13324) expanded the TM and increased the cross-sectional area of the Schlemm's canal and thereby lowered the IOP through increased perfusion through the conventional outflow tissues. 


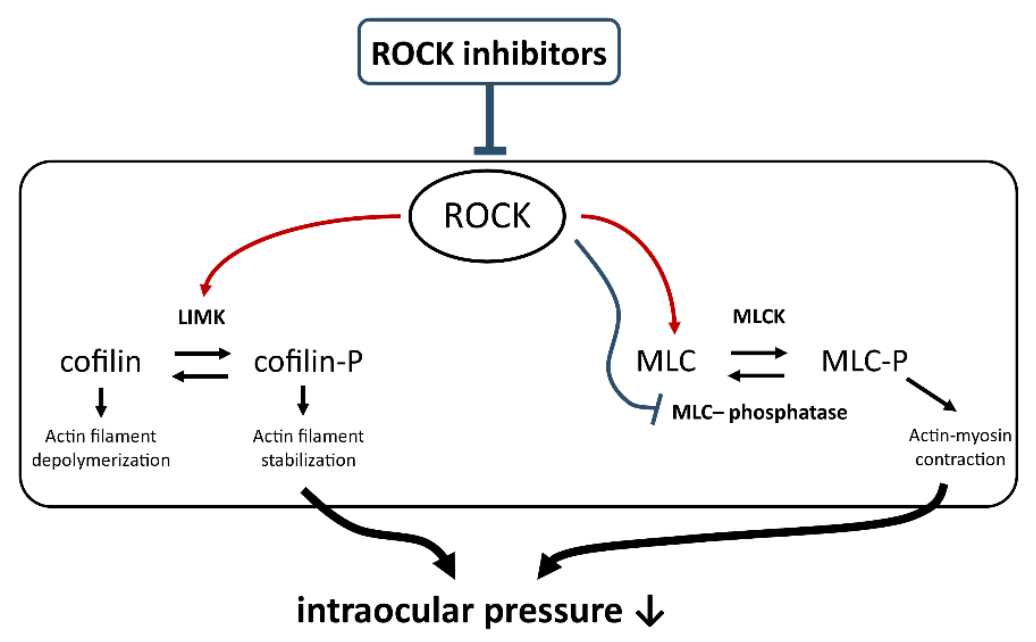

Figure 2. Proposed mechanism of ROCK inhibition in lowering intraocular pressure. (MLCP: myosin light chain phosphatase, MLC: myosin light chain, MLCK: myosin light chain kinase, LIMK: LIM kinases)

Filtration surgery: Accumulating data suggests that ROCK inhibitors enhance the success rate of glaucoma filtration surgery through inhibition of TGF- $\beta$-induced scarring. A frequent reason for failed filtration surgery is excessive postoperative scarring, which closes off the bypass for aqueous humor. As previously mentioned, TGF- $\beta$ is elevated in glaucoma. The cytokine has a crucial role in fibroblastmyofibroblast differentiation [49], which leads to fibrosis after surgery. On the basis of in vitro studies with human fibroblasts from the Tenon capsule of the eye, Y27632 has been proposed to interfere with postoperative bleb formation through inhibition of cell contraction and fibroblast activation (transdifferentiation to myofibroblasts) [50]. Recent in vitro results indicate that ripasudil also significantly diminishes the TGF- $\beta 2$-induced human conjunctival fibroblast activation, extracellular matrix expression, and collagen gel contraction [51]. Honjo et al. [50] performed a sclerostomy in rabbits and demonstrated that $10 \mathrm{mM}$ Y27632 applied topically for seven days improved the surgical outcome by inhibiting fibrosis and decreasing collagen deposition in the surgical area compared to vehicle-treated eyes.

\section{Recent status of ROCK inhibitors in clinical application}

Given the fact that ripasudil is marketed in Japan as a possible second-line treatment for glaucoma and ocular hypertension [2], the recent clinical trials for ROCK-inhibitor based anti-glaucoma drugs may be promising.

In completed clinical trials, twice daily application of $0.4 \%$ ripasudil proved to be safe and effective from the viewpoint of lowering the IOP [52-54]. Furthermore, an 8 week study (with four hundred and thirteen patients) pointed out that ripasudil has additional pressure-lowering effects when combined with betablockers or prostaglandin analogues [55]. Although ripasudil with beta-blockers and prostaglandin analogues has an additive effect, pilocarpine (another anti-glaucoma eyedrop) seems to diminish the ripasudil IOP lowering effect in mice eyes in the case of concomitant administration of ripasudil and pilocarpine [56].

A common adverse effect of ROCK inhibitor treatment is mild or moderate hyperemia, which resolves spontaneously in hours. Hyperemia is attributed to the vasodilatatory effect of ROCK inhibitors on conjunctival blood vessels. In addition to the relatively harmless hyperemia, a one-year study [57] revealed that after 8 weeks of ripasudil instillation there is an occurrence of allergic blepharitis (20\%) and conjunctivitis (17\%); some patients left the study due to these adverse events. Moreover, lens opacity was observed in mammals treated with high concentrations of ripasudil in preclinical studies. Cataract 
progression in humans was not noted as drug-related; clinicians diagnosed lens opacity change as a natural progression of age-related senile cataract [57]. The same one-year study did not report any adverse corneal effects. Nakagawa et al. [58] however, observed reversible pseudo-guttae-like corneal endothelial changes during one week twice daily topical instillation of $0.4 \%$ ripasudil in healthy humans. One and a half hours after ripasudil administration, non-contact specular microscopy showed drug-related morphological changes in corneal endothelium, which disappeared within 6 hours. These findings were in line with an animal model [59]: rabbits exhibited indistinct corneal endothelial cell borders one hour after instillation of a ROCK inhibitor, similar to human subjects. These abnormalities resolved to normal within hours. Using scanning and transmission electron microscopy, protrusions along the intercellular cell borders were observed, probably caused by the decreased actin-myosin contractility of corneal endothelial cells from ROCK inhibition. Physicians should be aware that ripasudil can cause transient guttae-like formation in the cornea, in order to avoid misdiagnosing patients as having chronic corneal endothelial disease such as Fuchs-endothelial dystrophy. Taken together, it appears that further studies are needed to explore the possible long-term side effects of ripasudil treatment.

Among the ongoing clinical trials with other ROCK inhibitors the most promising is AR13324 (also known as netarsudil or rhopressa), developed by Aerie Pharmaceuticals [13]. AR13324 is a so called dual-acting drug; the ROCK inhibitor part diminishes the IOP by increasing the outflow through the trabecular meshwork and the norepinephrine transporter (NET) inhibitor decreases the production of the aqueous humor. From animal models, the IOP-lowering effect of once daily $0.04 \%$ AR13324 was certified as effective $[60,46]$. However, during the first human study, a $0.02 \%$ concentration of AR13324 seemed to be the most potent and produced the best dose-response curve from the viewpoint of IOP reduction [61]. Eighteen healthy volunteers were involved in a phase I clinical study to evaluate the ocular and systemic safety of the drug. A once daily $0.02 \%$ AR13324 application in the morning for eight days was without any systemic side effect. Moreover, the pressure-lowering effect was maintained for more than 24 hours after the end of the treatment, which is unique. Surprisingly the drug was notably less effective on day one compared to day eight [62]. Two hundred and thirteen patients with primary open-angle glaucoma and ocular hypertension completed a 28-day trial with AR13324. Once daily $0.02 \%$ AR13324 was a little less effective than latanoprost (0.005\%) in pressure-lowering efficacy [63]. AR13324 (0.02\%) once and twice daily was also compared to timolol instilled twice daily in 3 month-long trials (called Rocket I and Rocket II). Rocket II achieved the primary endpoint and was non-inferior to timolol application. Two additional trials are in process: Rocket III is a one-year safety study in Canada and Rocket IV is a three month non-inferiority study comparing once daily AR13324 to twice-daily timolol with a six month follow-up safety evaluation [15].

Aerie Phamaceuticals has also developed a triple-action anti-glaucoma eye drop named PG324 (synonym roclatan), which is a fixed-dose combination of AR13324 (0.02\%) with latanoprost $(0.005 \%)$. Two hundred and ninety-two patients completed a 28 -day trial, where $0.01 \%$ and $0.02 \%$ roclatan proved to be a clinically and statistically more efficacious and safe hypotensive agent relative to its single components [14]. There are several phase III clinical trials with roclatan expected to begin or already enrolling patients. Mercury I is a one-year safety trial and Mercury II is a three months efficacy study, both of them comparing roclatan to AR13324 and latanoprost in the United States. Mercury III will evaluate six months safety and efficacy of the new drug relative to another clinically used fixed-dose combination hypotensive eye-drop in Europe [15].

AMA0076, designed by Amakem, is called a soft ROCK inhibitor (see definition in introduction), because its effects are localized thereby resulting in fewer side effects. The compound contains a carboxylic ester 
group and exhibits high ROCK efficacy (ROCK II IC50=2.5 nM) [7]. Topically instilled drug, once it gets through the cornea into the aqueous humor, remains stable. However, drug on the surface of the eye (in conjunctiva and other tissues) undergoes rapid metabolic inactivation by esterase. A notable advantage of this ROCK inhibitor is that the degree of hyperemia is significantly less than any of the other candidates, thus improving the tolerability profile. In in vitro human trabecular meshwork cultures, AMA0076 exposure temporarily altered cell shape through significant reduction in actin stress fibers and focal adhesions. In New Zealand white rabbits, $0.1,0.3$ and $0.5 \%$ eye-drop concentrations all proved to be more efficient in lowering intraocular pressure than the same concentrations of Y39983 [8]. Human trials were completed recently (ClinicalTrials.gov identifier: NCT02003547, NCT01693315, NCT02136940). In the first human trials, AMA0076 proved to be safe and efficient in IOP reduction with no significant conjunctival hyperemia associated with the treatment; results from the last, four week-long phase lla clinical study have not yet been published.

Despite the early favorable outcomes of animal or human studies, development of many ROCK inhibitors for clinical use in glaucoma have failed or been suspended. For instance, AR12286 (developed by Aerie Pharmaceuticals) completed a Phase lla human study, and produced significant dose-dependent IOP reduction [64], however no further human trials have been initiated. Y39983 (also called RKI-983, SNJ-1656) proved to be safe and an efficient hypotensive agent in rabbits [8], in monkeys [9] and in humans [65]. However, a seven day-long phase II clinical trial with 66 patients revealed unexpected side effects related to the drug instillation such as punctate keratitis, headache, and hepatic dysfunction [11]. INS117548 (developed by Inspire Pharmaceuticals) was abandoned after completion of a phase I clinical trial (ClinicalTrials.gov identifier: NCT00767793), probably because the twice daily administration was reported to cause ocular burning and stinging in a dose-dependent manner [66]. A phase lla clinical trial was completed with ATS907 (ClinicalTrials.gov identifier: NCT01668524), and the next trial begun (ClinicalTrials.gov identifier: NCT01520116). However, the company closed in February 2013, and no results from this trial have been disclosed.

Nonetheless, the number of ROCK inhibitors being tested for patient use provides hope that a new therapeutic drug will be achieved soon.

\section{Retina}

\section{Diabetic retinopathy}

In the past few years, RhoA and ROCK has been implicated in the pathogenesis of diabetic retinopathy. The basic problem is the long-term glucose homeostasis imbalance, which leads to an accumulation of advanced glycation end products in the vessels. This accumulation leads to structural changes including vascular rigidity and hyperpermeability. The damaged vessels are not able to provide sufficient blood supply, potentially causing hypoxia. Under these circumstances new vessel growth is promoted, however the structure of the new vessels is different than the normal, physiological vasculature.

In vitro studies on rhesus macaque retinal endothelial cells showed that high glucose levels induced increased RhoA activity and endothelial permeability, through altered expression of tight junction proteins; both fasudil and Y27632 reversed the high glucose-related changes [67]. Higher ROCK expression accompanied by increased stiffness occurred in diabetic mouse retinal capillaries and also in high glucosetreated retinal endothelial cell cultures [68]. The stiffer high glucose-treated retinal endothelial cells also exhibited lower expression and activity of the mechanosensitive ion channel TRPV4 (transient receptor potential vanilloid). ROCK inhibition resulted in significant recovery of TRPV4 expression and activity, as 
well as enhanced endothelial NO production and decreased monocyte adhesion to the endothelium [68]. In diabetes, endothelial nitric oxide synthase activity is reduced. Fasudil can significantly reverse this change through increased eNOS phosphorylation and thereby contributes to vasodilatation and vasculoprotection $[69,70]$. Changes in leukocyte adhesion to endothelium are a feature of the early stages of the disease. Bhaskaran et al. [71] suggest that high glucose-induced endothelial monocyte adhesion contributes, at least in part, to increased stiffness of retinal endothelial cells and subendothelial matrix. Human retinal endothelial cells co-cultured with activated monocytes for 24 and 72 hours significantly increased ROCK expression and activity along with impaired TRPV4 activity and expression [71]. In vitro and intravitreal administration of fasudil in a diabetic animal model mitigated the leukocyte-induced microvascular damage through decreasing both ICAM-1 (intercellular adhesion molecule-1) expression on the endothelium and CD $18 \mathrm{a} / 11 \mathrm{~b}$ presentation on the neutrophil granulocytes $[69,70]$. Thus ROCK inhibition reverses many of the changes seen in the retinal vessels in diabetes.

Monickaraj et al. [72] reported that patients suffering from manifest diabetic macular edema, a consequence of diabetic retinopathy, had elevated cathepsin D levels in their serum. The protease caused mechanical disruption of the endothelial barrier through increased RhoA-ROCK-dependent contractility in human retinal endothelial cells. Application of a ROCK inhibitor (Y27632) diminished the effect of monocyte-derived cathepsin D on endothelial cell permeability. Rothschild et al. [73] hypothesized that Rho-pathway activation is involved in the pathogenesis of diabetic macular edema through breakdown of the retinal pigment epithelial (RPE) cell barrier. In their diabetic rat model, Rho pathway activation caused cytoskeletal remodeling (apical constriction and stress fiber formation) in RPE cells, leading to intercellular junction opening. Intravitreally applied fasudil reversed the morphologic abnormalities and improved the barrier integrity.

In later phases, neovascularization and proliferative vitreoretinopathy (PVR) are hallmarks of the progression of the disease. Cicatricial contraction of the fibrous membrane can lead to tractional retinal detachment with severe vision loss. Patients suffering from proliferative retinal disease have a significantly higher vitreal concentration of TGF- $\beta 2$, than patients with non-proliferative diseases [74,75]. Activated TGF$\beta 2$ has been implicated in contraction of the fibrous membrane through MLC phosphorylation mediated by ROCK. In an experimental PVR rabbit model, intravitreal injection of fasudil ( $30 \mu \mathrm{M})$ effectively suppressed this destructive progression, even after the proliferative membranes formed or connected to the retina [76]. Furthermore, in another PVR rabbit model, multiple intravitreal injections of Y27632 (targeted intraocular concentration was $50 \mu \mathrm{M}$ ) decreased the development of tractional retinal detachment (Figure 3) [77].

Because vascular endothelial growth factor (VEGF) has been shown to play a pivotal role in macular edema and retinal neovascularization, anti-VEGF therapy has been widely used for the treatment of agerelated macular degeneration and diabetic retinopathy in clinical studies. However, in many cases, satisfying visual or anatomical improvements are not achieved. Moreover, the treatment has many possible adverse local and systemic effects, such as IOP elevation, inflammation, hypertension, myocardial infarcts or cerebrovascular accidents. In 2008 was the first report, from in vivo mouse cornea, that fasudil had inhibitory potential in ocular angiogenesis [38]. Additional evidence from human foreskin [78] and retinal microvascular endothelial cell cultures [10] has demonstrated that RhoA or Rho kinases are involved in VEGF-induced cytoskeletal changes and cell migration. Increased RhoA activity was accompanied by elevated phosphorylation and activity of the VEGF receptor-2, which might be the connection between RhoA pathways and VEGF effects [78]. In 2014, in an experimental diabetes rabbit model, the effect of a 
single intravitreal injection of fasudil or bevacizumab on VEGF levels was evaluated. According to Celik et al. [79], fasudil reduced the VEGF levels, however not as efficiently as bevacizumab. There are pilot clinical studies which have evaluated the feasibility of fasudil combined with bevacizumab as an intravitreal injection in diabetic macular edema. During one short-term study, 15 patients suffering from diabetic macular edema received an intravitreal injection of $0.025 \mathrm{mg}$ fasudil combined with $1.25 \mathrm{mg}$ bevacizumab; the targeted intraocular concentration of the drug was $10 \mu \mathrm{M} / \mathrm{L}$. One month later visual acuity and central macular thickness were measured. The best corrected visual acuity improved on average by $40 \%$, and the central macular thickness decreased by approximately $20 \%$, without any adverse complications [80] . These results confirmed findings shown in a previous smaller trial [81]. Moreover, $0.4 \%$ and $0.8 \%$ ripasudil eye drops applied topically 3 times daily for 5 days decreased not just the neovascular area, but the avascular area also, in a hypoxia-induced diabetic retinopathy mice model. In contrast, $0.4 \%$ fasudil eye drops did not show any effect. Additional experiments which tested normal vascularization found that ROCK inhibitors did not affect physiological angiogenesis, although they did modify pathological vascular growth in a retinopathy model [10].

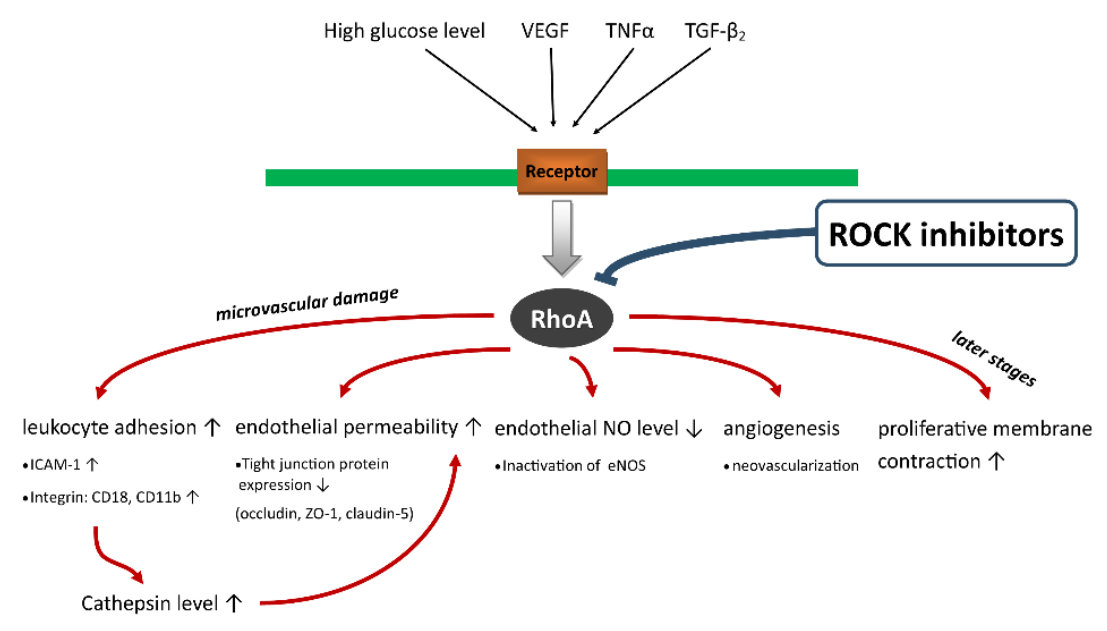

Figure 3. Proposed Rho-ROCK pathway in the pathogenesis of diabetic retinopathy

\section{Age-related macular degeneration (AMD)}

Age-related macular degeneration (AMD) is a degenerative disorder and one of the most frequent causes of irreversible visual loss in industrialized countries. The etiology of the disease has been extensively investigated over the last decades, however we are still far from a complete understanding. The conventional classification distinguishes two different subtypes: dry AMD with atrophic lesions and an exudative, wet form with neovascularization. The crucial difference between the two subtypes is the development of choroidal neovascularization (CNV), the formation of new vessels characterized by inflammation and fibrosis, in wet AMD.

Zandi et al. [82] suggest that ROCKs may contribute to the AMD pathomechanism through macrophage differentiation in the aging eye. Their theory is supported by the following results. Intravitreally injected undifferentiated MO macrophages did not affect the area of neovascularization (CNV) in mice eyes, however M1 macrophages decreased the area of the CNV whereas M2 macrophages increased the size of the lesion. In these animals repeated intravitreal injections of fasudil (ROCK I and ROCK II inhibitor) or KD025 (specific ROCK II inhibitor) decreased the area of the CNV, however only the selective ROCK II inhibitor increased markers of M1-type macrophages. Taken together the authors assume that with aging the fundus cytokine environment changes stimulated by increased ROCK II signaling, which may shift the 
macrophage transformation towards the M2 subtype, also called proangiogenic MaDAMs (Macular degeneration associated macrophages). Selective ROCK II inhibitors may help to restore the macrophage balance to that found in healthy, young eyes and reduce CNV. On the other hand, in monkeys, intravitreal injection of fasudil ( $30 \mu \mathrm{M} / \mathrm{l} 3$ times per week) still significantly decreased the thickness of and vascular leakage from the CNV membrane [82].

A novel and potent ROCK inhibitor AMA0428, from Amakem Therapeutics, has been shown to not only reduce the angiogenesis, but also inhibit inflammation and fibrosis in a mouse neovascular AMD model. In various human cell cultures (Human umbilical vein endothelial cells=HUVECs, human brain microvascular endothelial cells=HBMECs, Human brain vascular pericytes =HBVPs) administration of AMA0428 inhibited the VEGF-stimulated migration of endothelial cells (HUVECS, HBMECS) and stimulated pericyte recruitment. These in vitro data support the concept that ROCK inhibition contributes to the maturation of blood vessels, and might be able to reduce new blood vessel formation. In a mouse laser-induced CNV model, a single intravitreal injection of AMA0428 $(100,1000 \mathrm{ng})$ administered either at time 0 or day 3 significantly reduced the inflammation examined on day 5, while the VEGF-2 receptor inhibitor (DC101) had no effect. Fourteen days after CNV induction, repeated intravitreal injections of AMA0428 (100 or 1000ng on days 0, 4,10 ) had a remarkable inhibitory effect on angiogenesis and vessel leakage similar to anti-VEGF (DC101) treatment. Moreover, one month after the laser injury, multiple intravitreal administrations of this ROCK inhibitor (100 or $1000 \mathrm{ng}$, on days $0,4,10,20$ ) significantly reduced fibrosis in the mouse CNV model whereas the VEGF-receptor 2 inhibitor (DC101) had no effect [16].

AR13154 is a selective multi-kinase inhibitor, which inhibits ROCK, Janus kinase (JAK) and plateletderived growth factor- $\beta$ (PDGF- $ß$ ). This compound significantly decreased neovascularization in laserinduced rat and hypoxia-induced mouse models. In rats, CNV was induced on day 0, and then AR13154 or vehicle was injected intravitreally on days $1,4,10$; aflibercept $(800 \mathrm{ug} / \mathrm{ml})$ was used as a positive control and injected into the vitreous cavity only on the first day. AR13154 reduced the mean lesion size by $35 \%$, whereas the aflibercept administration achieved a $23 \%$ reduction. In a mouse hypoxia-induced optic retinopathy model, topical administration of $0.06 \%$ AR13154 decreased the area of neovascularization by $37 \%$, a level similar to the intraperitoneally applied aflibercept. The combination of the two drugs resulted in a $57 \%$ reduction of lesion [83]. Additional combinations of drugs, including selective ROCK II inhibitors, may be of interest in the future.

\section{Optic nerve blood flow, neuroprotection, retinal detachment}

Besides the previously described mechanisms, clinical application of ROCK inhibitors has other potential benefits. For instance, ROCK inhibitors cause vasodilatation through smooth muscle relaxation and regulation of endothelial nitric oxide synthase (eNOS). Impaired blood flow around the optic disc and in the posterior segment has been reported in several conditions such as glaucoma, non-arteritic anterior ischemic optic neuropathy (NAION) and diabetic retinopathy. The optic disc blood flow is mainly supplied by the posterior ciliary arteries. Topical and intravenously applied fasudil ameliorated the eNOS inhibitorinduced optic nerve blood flow impairment in rabbits, while no significant effect on normal blood flow was detected [84]. Also in rabbits, ROCK inhibitors (Y27632, Y39983) showed a vasodilatatory effect on ciliary artery segments, even when the NO mediated route of vasodilatation was blocked [85]. NAION affects the anterior part of the optic nerve and is related to an altered blood supply of this area. Intravitreal fasudil $(0.025 \mathrm{mg} / 0.05 \mathrm{ml}$, calculated to be equivalent to $10 \mu \mathrm{M} / \mathrm{L})$ was used in a pilot study with 13 recent-onset NAION patients and seemed to facilitate a cure from the disease. More than $70 \%$ of the patients showed significant recovery of visual acuity within one month after the injection, which is an outstanding result 
compared to previous reports of other treatment options for NAION. The small sample size and the lack of a control group is a limitation of this study, nonetheless, the outcomes are promising and should encourage further investigation [86]. In the posterior segment, intravitreal ripasudil (calculated intravitreal concentrations were 1 and $100 \mu \mathrm{M}$ ) in cats increased retinal blood flow and blood velocity without showing effect on vessel diameter [87].

Neuroprotection: Yang et al. [88] demonstrated in rats that two weeks after optic nerve injury RhoA, ROCK I and ROCK II expression were increased. These increases were diminished by Y39983 (applied intravitreally $20 \mu \mathrm{M}$ on day 0 and 7). But in addition, the ROCK inhibitor enhanced the number of surviving retinal ganglion cells, thereby preventing axonal degeneration $500 \mu \mathrm{m}$ from the crush site. In 2007, Sagawa et al.[89] compared two ROCK inhibitors in feline retinal cultures. Whereas $10 \mu \mathrm{M} Y 39983$ facilitated the extension of neurites and glial processes, Y27632 had a similar effect only when the dose was increased to $100 \mu \mathrm{M}$. Based on their in vitro results they continued the experiment in an in vivo cat optic nerve crush model in which $10 \mu \mathrm{M}$ Y39983 was injected intravitreally. Not only the immediate injection, but also the repeated intravitreal administration on day seven significantly increased (at least doubled) the number of regenerated axons which were able to grow through the crush site. On the other hand, at week six, the number of axon fibers at the crush site was almost the same as that observed at week two. Thus repeated injections of Y39983 seemed to facilitate axon regeneration in the first two weeks after the nerve trauma; perhaps additional administration of the ROCK inhibitor would have been beneficial. However, reduction in activated RhoA levels [89] may reduce the protection to neurons of longer treatments.

Ichikawa et al. [90] conducted similar experiments comparing the effect of different doses of Y27632 and fasudil in in vitro and in vivo cat optic nerve injury models. Interestingly, in culture conditions both $10 \mu \mathrm{M}$ and $30 \mu \mathrm{M}$ fasudil or Y27632 enhanced neurite extension, however $100 \mu \mathrm{M}$ fasudil application resulted in neurite outgrowth inhibition, while $100 \mu \mathrm{M}$ Y27632 exhibited the highest number of processes. In in vivo experiments, fasudil treated eyes did not show newly regenerated axon fibers in the crush site, whereas 10 and $100 \mu \mathrm{M}$ Y27632 significantly facilitated neurite outgrowth beyond the crush site. In rabbits intravenous fasudil ameliorated optic nerve injury related degenerative molecular and morphological changes compared to the dexamethasone and saline treated group. In this experiment, NogoA (known as a nerve growth inhibitor) and caspase 3 (known to take part in apoptosis) levels were measured; expression of both factors was decreased by fasudil along with RhoA and ROCK II levels. Moreover, at every time point, (on day $3,7,14,21$ ) but especially after one week, the optic nerve trauma related changes, such as retinal ganglion cell nuclei degeneration and cell loss and thinning of the retina, were less severe in the fasudiltreated group [91]. In salamander retinal cultures $100 \mu \mathrm{M}$ Y27632 had different effects on photoreceptors depending on cell type [92]. For rods, it inhibited axonal retraction and slightly enhanced the rod process outgrowth; but for cones, it significantly increased the number of new process and the development of presynaptic varicosities.

Temporary or permanent ischemia or trauma to the optic nerve leads to oxidative stress with elevated levels of reactive oxygen species contributing to neurodegeneration. Yamamoto et al. [93] described, in a mouse optic nerve crush model using orally administered ( $1 \mathrm{mg} / \mathrm{kg} / \mathrm{day}$ ) fasudil or ripasudil, the amelioration of retinal ganglion cell death. The specificity of ripasudil for ROCK was found to be 2-18 times higher than fasudil. On the basis of their results, they proposed a pathway leading to retinal ganglion cell death prevention which started with suppression of NOX1 (NADPH oxidase) expression by ROCK inhibition and resulted in decreased synthesis of reactive oxygen species, and thereby, neuroprotection.

Retinal detachment: In the above examples the purpose of using ROCK inhibitors was to increase the 
plasticity and growth of axons after the injury. For retinal detachment the goal is to prevent structural remodeling and plasticity in order to decrease disruption of synapses [94]. Photoreceptor degeneration was shown to be one of the early changes after detachment in the feline retina [95]. However, all photoreceptors did not respond in the same way. While rods rapidly started to retract their synaptic terminals towards their cell bodies thereby breaking their synaptic connection to horizontal and bipolar cells, cones exhibited degenerative signs later. Cones did not show retraction [95], but instead changed the shape of their terminals [94]. Similar changes were described in human retina [96]. Disruption of the first synapse in the visual pathway between the photoreceptors and the bipolar cells may be one reason for the imperfect visual recovery seen after successful reattachment surgery.

RhoA was shown to be present in the inner and the outer retina of salamanders [97], and pigs [94]. From both in vitro and in vivo experiments, the RhoA-ROCK pathway was shown to take part in structural remodeling of photoreceptors, including rod axon retraction and cone neuritic outgrowth. In salamander retinal cultures, rods retract their axons by 24 hours. However, rods maintained their morphology and showed no axonal retraction with $100 \mu \mathrm{M}$ Y27632 pretreatment [97] and in similar conditions with even lower concentrations $(10,30,100 \mu \mathrm{M})$ in a dose-dependent manner [98]. An in vitro retinal detachment model in porcine eyes demonstrated that RhoA activity increased immediately after detachment $[94,99]$; recent experiments, therefore, have explored short time periods after the detachment injury. Porcine retinal explants treated with 1, 10 and $100 \mu \mathrm{M}$ of Y27632 significantly reduced the number of the rod synaptic terminals which retracted into the outer nuclear layer, moreover six hour-delayed administrations of $100 \mu \mathrm{M}$ Y27632 also reduced synaptic breakage [94]. In a live pig model of retinal detachment, Y27632 or fasudil was injected subretinally. One and $10 \mathrm{mM}$ of Y27632 and $10 \mathrm{mM}$ of fasudil achieved significant prevention of rod axonal remodeling in the detached area of the treated eye compared to the detached area of the fellow non-treated eye. In this model Y27632 also seemed to be more effective than fasudil: 10 $\mathrm{mM}$ Y27632 had significant effect on prevention of synaptic changes in both detached and non-detached retinal areas, compared to the control areas from the drug-free eye, whereas fasudil prevented synaptic retraction only in the detached area of retina [99], [unpublished data]. In vitro findings also suggest that other kinases in the RhoA/ROCK pathway, specifically Lim kinase (LIMK), play a role in structural remodeling of photoreceptors and could be future therapeutic targets after retinal detachment [98]. 


\section{Conclusions}

This review has collected the publications from the last few years related to the application of ROCK inhibitors in various ocular diseases. Their potential beneficial effects are presented in Table 2 .

Table 2. Beneficial effects of ROCK inhibitors in various ocular disorders.

\section{CORNEA}

$\uparrow$ Corneal endothelial cell survival, migration, adhesion, proliferation

$\uparrow$ Endothelial markers related to pump function

$\downarrow$ Size of corneal endothelial wound

$\downarrow$ Corneal edema (central corneal thickness)

$\downarrow$ Cornea neovascularization

$\uparrow$ Healing of corneal epithelial defect

\begin{tabular}{|c|}
\hline GLAUCOMA \\
\hline$\downarrow$ IOP - 个Outflow facility \\
\hline 个Cross sectional area and permeability of Sclemm's canal \\
\hline$\downarrow$ Fibrosis and postoperative scarring at surgical area \\
\hline$\uparrow$ Neuroprotection of retina \\
\hline
\end{tabular}

\section{RETINA}

\begin{tabular}{cl}
\hline Diabetic retinopathy & $\downarrow$ Leukocyte adhesion, endothelial permeability \\
& $\uparrow$ eNO level \\
& $\downarrow$ Neovascularization \\
& $\downarrow$ Proliferative membrane contraction \\
\hline AMD & $\downarrow$ Angiogenesis, fibrosis and inflammation \\
\hline Optic nerve injury & $\uparrow$ Increasing optic nerve blood flow \\
& $\downarrow$ Degenerative and morphological changes \\
& $\uparrow$ Axon regeneration \\
\hline Retinal detachment & $\uparrow / \downarrow$ Extension of neurite and glial processes / neurite \\
& outgrowth \\
& $\uparrow$ Photoreceptor process outgrowth \\
& $\downarrow$ Rod axon retraction
\end{tabular}

For corneal endothelial wound healing and glaucoma further/continued investigation is necessary to address pharmacodynamics, safety and tolerability. But already accumulating evidence from in vitro and in vivo studies shows that fasudil, ripasudil and other ROCK inhibitors may be promising in prevention or treatment of these and other retinal disorders (i.e., diabetic retinopathy, AMD) or injuries (e.g., retinal detachment), in part because the Rho/ROCK pathway is deeply involved in their pathogenesis. Moreover, the benefit of ROCK inhibition may be increased by the fact that the inhibitors often target pathological change specifically and have no effect on normal processes. For instance, ROCK inhibition has no effects on control cornea [37], normal blood flow [84] and normal angiogenesis [10]. Constitutive ROCK activity may be low in many ocular tissues. However, there are important unanswered questions.

First of all, we need to determine the optimal therapeutic intraocular concentration of ROCK inhibitor. Then we must consider the best and most feasible method of drug administration. Because of the short biological half-life $[2,7,100]$ of ROCK inhibitors, repeated applications of intravitreal injections or eye drops will be necessary. Intravitreal implantation of a slowly releasing drug delivery system may offer an 
alternative solution. Some inhibitors may prove more useful than others because of their tissue interactions. For instance, topically instilled $0.4 \%$ and $0.8 \%$ ripasudil were shown to reach the posterior segment in sufficient concentration to affect neovascularization, whereas $0.4 \%$ fasudil did not. Preparation of $0.8 \%$ fasudil eye drops was not feasible because of poor solubility at this concentration [10]. Further chemical modification of drugs such as liposomal encapsulation [101,102], or other types of conjugations [103], may be able to enhance in vivo efficacy in the future.

Furthermore, the timing of the treatment may be important. Since anti-VEGF therapy is used in advanced phases of neovascular disease, ROCK inhibitors may be useful to prevent structural changes in earlier stages and may affect a broader spectrum of viable targets. In most disease models we also still need to learn about the time course of RhoA and/or ROCK activity. In the case of our retinal detachment model we are aiming to answer similar questions. Although we know RhoA activation starts quickly we do not know, for in vivo injury, when it peaks and how long activity is above normal. For instance, how many injections of a ROCK inhibitor will be necessary to not only prevent photoreceptor synaptic remodeling but allow restoration of normal vision after detachment and what is the optimal time-window and therapeutic dose for treatment.

We also are investigating whether more than one component of the RhoA/ROCK pathway can be targeted simultaneously and with what effect. Early studies indicate that a combination of ROCK and LIMK inhibition may be a more effective treatment than either alone in our retinal detachment model $[98,104]$. However, in spite of remaining questions, improvements in treatment of ocular disease with ROCK inhibition seem imminent.

Acknowledgements: The authors gratefully acknowledge support from NIH grant EY021542.

\section{References}

[1] Y. Feng, P. V. Lograsso, O. Defert, R. Li, J. Med. Chem. 59 (2016) 2269-2300.

[2] K. P. Garnock-Jones, Drugs 74 (2014) 2211-2215.

[3] S. K. Wang, R. T. Chang, Clin. Ophthalmol. 8 (2014) 883-890.

[4] T. Ishizaki, M. Uehata, I. Tamechika, J. Keel, K. Nonomura, M. Maekawa, et al., Mol. Pharmacol. 57 (2000) 976-983.

[5] M. Uehata, T. Ishizaki, H. Satoh, T. Ono, T. Kawahara, T. Morishita, et al., Nature 389 (1997) 990-4.

[6] Y. Kaneko, M. Ohta, T. Inoue, K. Mizuno, T. Isobe, S. Tanabe, et al., Sci. Rep. 6 (2016) 19640.

[7] S. Boland, O. Defert, J. Alen, A. Bourin, K. Castermans, N. Kindt, et al., Bioorg. Med. Chem. Lett. 23 (2013) 6442-6446.

[8] S. Van de Velde, T. Van Bergen, D. Sijnave, K. Hollanders, K. Castermans, O. Defert, et al., Invest. Ophthalmol. Vis. Sci. 55 (2014) 1006-1016.

[9] H. Tokushige, M. Inatani, S. Nemoto, H. Sakaki, Invest. Ophthalmol. Vis. Sci. 48 (2007) 3216-3222.

[10] M. Yamaguchi, S. Nakao, R. Arita, Y. Kaizu, M. Arima, Y. Zhou, et al., Invest. Ophthalmol. Vis. Sci. 57 (2016) 2264-2276.

[11] T. Inoue, H. Tanihara, H. Tokushige, M. Araie, Acta Ophthalmol. 93 (2015) e393-e395.

[12] J. H. Lee, Y. Zheng, D. von Bornstadt, Y. Wei, A. Balcioglu, A. Daneshmand, et al., Ann. Clin. Transl. Neurol. 1 (2014) 2-14.

[13] J. M. Sturdivant, S. M. Royalty, C. W. Lin, L. A. Moore, J. D. Yingling, C. L. Laethem, et al., Bioorganic Med. Chem. Lett. 26 (2016) 2475-2480.

[14] R. A. Lewis, B. Levy, N. Ramirez, C. C Kopczynski, D. W. Usner, G. D. Novack, Br. J. Ophthalmol. 100 (2016) 339-344.

[15] J. Bacharach, Glaucoma Today (2016) 43-45. 
[16] K. Hollanders, T. Van Bergen, N. Kindt, K. Castermans, D. Leysen, E. Vandewalle, et al., Invest. Ophthalmol. Vis. Sci. 56 (2015) 1335-1348.

[17] K. Riento, A. J. Ridley, Nat. Rev. Mol .Cell. Biol. 4 (2003) 446-456.

[18] T. Leung, X. Q. Chen, E. Manser, L. Lim, Mol. Cell. Biol. 16 (1996) 5313-5327.

[19] M. F. Olson, Curr. Opin. Cell Biol. 20 (2008) 242-248.

[20] A. P. Somlyo, A. V Somlyo, J. Physiol. 522 Pt 2 (2000) 177-85.

[21] M. Amano, M. Ito, Y. Fukata, K. Chihara, T. Nakano, Y. Matsuura, et al., J. Biol. Chem. 271 (1996) 20246-20249.

[22] K. Kimura, M. Ito, M. Amano, K. Chihara, Y. Fukata, M. Nakafuku, et al., Science 273 (1996) 245-248.

[23] M. Maekawa, Science (80-. ). 285 (1999) 895-898.

[24] M. Amano, Y. Fukata, K. Kaibuchi, Exp. Cell Res. 261 (2000) 44-51.

[25] Y. Shimizu, D. Thumkeo, J. Keel, T. Ishizaki, H. Oshima, M. Oshima, et al., J. Cell Biol. 168 (2005) $941-$ 953.

[26] D. Thumkeo, J. Keel, T. Ishizaki, M. Hirose, K. Nonomura, H. Oshima, et al., Mol. Cell. Biol. 23 (2003) 5043-55.

[27] D. Thumkeo, Y. Shimizu, S. Sakamoto, S. Yamada, S. Narumiya, Genes to Cells 10 (2005) 825-834.

[28] C. Fukiage, K. Mizutani, Y. Kawamoto, M. Azuma, T. R. Shearer, Biochem. Biophys. Res. Commun. 288 (2001) 296-300.

[29] N. Okumura, M. Ueno, N. Koizumi, Y. Sakamoto, K. Hirata, J. Hamuro, et al., Invest. Ophthalmol. Vis. Sci. 50 (2009) 3680-3687.

[30] N. Okumura, N. Koizumi, E. P. Kay, M. Ueno, Y. Sakamoto, S. Nakamura, et al., Invest. Ophthalmol. Vis. Sci. 54 (2013) 2493-2502.

[31] N. Okumura, R. Inoue, Y. Okazaki, S. Nakano, H. Nakagawa, S. Kinoshita, et al., Invest. Ophthalmol. Vis. Sci. 56 (2015) 6067-6074.

[32] Y. Q. Soh, G. Peh, B. L. George, X. Y. Seah, N. K. Primalani, K. Adnan, et al., Invest. Opthalmology Vis. Sci. 57 (2016) 338-348.

[33] N. Okumura, N. Koizumi, M. Ueno, Y. Sakamoto, H. Takahashi, H. Tsuchiya, et al., Am. J. Pathol. 181 (2012) 268-277.

[34] C. Bostan, M. Thériault, K. J. Forget, C. Doyon, J. D. Cameron, S. Proulx, et al., Invest. Ophthalmol. Vis. Sci. 57 (2016) 1620-34.

[35] N. Koizumi, N. Okumura, M. Ueno, H. Nakagawa, J. Hamuro, S. Kinoshita, Cornea 32 (2013) 11671170.

[36] N. Okumura, S. Nakano, E. P. Kay, R. Numata, A. Ota, Y. Sowa, et al., Invest. Ophthalmol. Vis. Sci. 55 (2014) 318-329.

[37] N. Okumura, Y. Okazaki, R. Inoue, K. Kakutani, S. Nakano, S. Kinoshita, et al., Invest. Ophthalmol. Vis. Sci. 57 (2016) 1284-1292.

[38] Y. Hata, M. Miura, S. Nakao, S. Kawahara, T. Kita, T. Ishibashi, Jpn. J. Ophthalmol. 52 (2008) 16-23.

[39] M. K. Fink, R. R. Mohan, S. Gupta, S. Ebers, E. Crider, M. Possin, et al., ROCK Inhibitor HA1077: Potently Inhibits Corneal Fibrosis and Neovascularization. in Annu. Meet. Assoc. Res. Vis. Ophtalmol., Seattle, United States of America, 2016, Abstract No.3481.

[40] P. Zeng, R. Pi, P. Li, R. Chen, L. Lin, H. He, et al., Mol. Vis. 21 (2015) 688-698.

[41] P. Vasantha Rao, P. F. Deng, J. Kumar, D. L. Epstein, Invest. Ophthalmol. Vis. Sci. 42 (2001) 10291037.

[42] B. A. Harrison, Z. Y. Almstead, H. Burgoon, M. Gardyan, N. C. Goodwin, J. Healy, et al., ACS Med. Chem. Lett. 6 (2015) 84-88.

[43] W. Noske, Graefe's Arch. Clin. Exp. Ophthalmol. 235 (1997) 551-552.

[44] R. C. Tripathi, J. Li, W. F. Chan, B. J. Tripathi, Exp. Eye Res. 59 (1994) 723-727. 
[45] T. Inoue, H. Tanihara, Prog. Retin. Eye Res. 37 (2013) 1-12.

[46] R. Wang, J. E. Williamson, C. Kopczynski, J. B. Serle, J. Glaucoma 24 (2015) 51-54.

[47] T. Isobe, K. Mizuno, Y. Kaneko, M. Ohta, T. Koide, S. Tanabe, Curr. Eye Res. 39 (2014) 813-22.

[48] G. Li, D. Mukherjee, I. Navarro, N. E. Ashpole, J. M. Sherwood, J. Chang, et al., Eur. J. Pharmacol. (2016) 1-12.

[49] F. Klingberg, B. Hinz, E. S. White, J. Pathol. 229 (2013) 298-309.

[50] M. Honjo, H. Tanihara, T. Kameda, T. Kawaji, N. Yoshimura, M. Araie, Invest. Ophthalmol. Vis. Sci. 48 (2007) 5549-5557.

[51] A. Futakuchi, T. Inoue, T. Fujimoto, M. Inoue-Mochita, M. Kawai, H. Tanihara, Exp. Eye Res. 149 (2016) 107-115.

[52] H. Tanihara, T. Inoue, T. Yamamoto, Y. Kuwayama, H. Abe, M. Araie, JAMA Ophthalmol. 131 (2013) 1288-1295.

[53] H. Tanihara, T. Inoue, T. Yamamoto, Y. Kuwayama, H. Abe, M. Araie, Am. J. Ophthalmol. 156 (2013) 731-736.e2.

[54] H. Tanihara, T. Inoue, T. Yamamoto, Y. Kuwayama, H. Abe, H. Suganami, et al., Acta Ophthalmol. 93 (2015) e254-e260.

[55] H. Tanihara, T. Inoue, T. Yamamoto, Y. Kuwayama, H. Abe, H. Suganami, et al., JAMA Ophthalmol. 133 (2015) 755-761.

[56] R. Yamagishi, M. Honjo, Y. Aoyama, T. Uchida, M. Aihara, Alterered interactions of concomitant administrations of ROCK inhibitor and parasympathetic agonist in mouse IOP and outflow dynamics, in Annu. Meet. Assoc. Res. Vis. Ophthalmol., Seattle, United States of America, 2016, Abstract No.3011-A0360.

[57] H. Tanihara, T. Inoue, T. Yamamoto, Y. Kuwayama, H. Abe, A. Fukushima, et al., Acta Ophthalmol. 94 (2016) e26-e34.

[58] H. Nakagawa, N. Koizumi, N. Okumura, H. Suganami, S. Kinoshita, PLoS One 10 (2015) 1-15.

[59] N. Okumura, Y. Okazaki, R. Inoue, S. Nakano, N. J. Fullwood, S. Kinoshita, et al., Invest. Opthalmology Vis. Sci. 56 (2015) 7560.

[60] J. W. Kiel, C. C. Kopczynski, J. Ocul. Pharmacol. Ther. 31 (2015) 146-151.

[61] M. Weiss, B. Levy, C. Kopczynski, T. Van Haarlem, G. Novack, A.-C. Study Group, Invest. Ophthalmol. Vis. Sci. 54 (2013) 754.

[62] B. Levy, N. Ramirez, G. D. Novack, C. Kopczynski, Am. J. Ophthalmol. 159 (2015) 980-985.

[63] J. Bacharach, H. B. Dubiner, B. Levy, C. C. Kopczynski, G. D. Novack, Ophthalmology 122 (2015) 302307.

[64] R. D. Williams, G. D. Novack, T. Van Haarlem, C. Kopczynski, Am. J. Ophthalmol. 152 (2011) 834841.e1.

[65] H. Tanihara, M. Inatani, M. Honjo, H. Tokushige, J. Azuma, M. Araie, Arch. Ophthalmol. 126 (2008) 309-315.

[66] J. Chen, S. A. Runyan, M. R. Robinson, Clin. Ophthalmol. 5 (2011) 667-677.

[67] Q.-Y. Lu, W. Chen, L. Lu, Z. Zheng, X. Xu, Int. J. Clin. Exp. Pathol. 7 (2014) 7268-7277.

[68] X. Yang, A. Bhaskaran, H. Scott, S. Ardekani, J. Xu, U. Mohideen, et al., Rho/ROCK-mediated Retinal Endothelial Stiffening Impairs TRPV4 Signaling and Promotes Diabetic Retinal Inflammation, in Annu. Meet. Assoc. Res. Vis. Ophthalmol., Seattle, United States of America, 2016, Abstract No.3220-C0020.

[69] R. Arita, Y. Hata, S. Nakao, T. Kita, M. Miura, S. Kawahara, et al., Diabetes 58 (2009) 215-226.

[70] R. Arita, S. Nakao, T. Kita, S. Kawahara, R. Asato, S. Yoshida, et al., Invest. Ophthalmol. Vis. Sci. 54 (2013) 2373-2383.

[71] A. Bhaskaran, X. Yang, H. Scott, K. Ghosh, Activated Monocytes contribute to the Mechanical Control of Diabetic Retinal Endothelial Activation, in Annu. Meet. Assoc. Res. Vis. Ophtalmol., Seattle, United States of America, 2016, Abstract No.3219-C0019. 
[72] F. Monickaraj, P. G. McGuire, C. Franco Nitta, K. Ghosh, A. Das, FASEB J. 30 (2016) 1670-1682.

[73] P.-R. Rothschild, S. Salah, E. Gelize, C. Bergin, M. Berdugo, C. Klein, et al., Diabetes-induced ROCK activation contributes to outer blood retinal barrier breakdown:implications for diabetic macular edema, in Annu. Meet. Assoc. Res. Vis. Ophthalmol., Seattle, United States of America, 2016, Abstract No. 6144.

[74] T. Kita, Y. Hata, K. Kano, M. Miura, S. Nakao, Y. Noda, et al., Diabetes 56 (2007) 231-238.

[75] T. B. Connor, A. B. Roberts, M. B. Sporn, D. Danielpour, L. L. Dart, R. G. Michels, et al., J. Clin. Invest. 83 (1989) 1661-6.

[76] T. Kita, Y. Hata, R. Arita, S. Kawahara, M. Miura, S. Nakao, et al., Proc. Natl. Acad. Sci. U. S. A. 105 (2008) 17504-9.

[77] Y. Zheng, H. Bando, Y. Ikuno, Y. Oshima, M. Sawa, M. Ohji, et al., Invest. Ophthalmol. Vis. Sci. 45 (2004) 668-674.

[78] G.P. Van Nieuw Amerongen, P. Koolwijk, A. Versteilen, V. W. M. Van Hinsbergh, Arterioscler. Thromb. Vasc. Biol. 23 (2003) 211-217.

[79] F. Celik, F. Ulas, Z. G. Ozunal, T. Firat, S. Celebi, U. Dogan, Int. J. Ophthalmol. 7 (2014) 57-61.

[80] R. Nourinia, H. Ahmadieh, M. H. Shahheidari, S. Zandi, S. Nakao, A. Hafezi-Moghadam, J. Ophthalmic Vis. Res. 8 (2013) 337-340.

[81] H. Ahmadieh, JAMA Ophthalmol. 131 (2013) 923-924.

[82] S. Zandi, S. Nakao, K. H. Chun, P. Fiorina, D. Sun, R. Arita, et al., Cell Rep. 10 (2015) 1173-1186.

[83] C.-W. Lin, J. M. Sturdivant, M. A. Delong, C. Kopczynski, Effectiveness of AR-13154 monotherapy and combination therapy in animal models of wet age-related macular degeneration and proliferative diabetic retinopathy, in Annu. Meet. Assoc. Res. Vis. Ophthalmol., Seattle, United States of America, 2016, Abstract No.287-B0320.

[84] T. Sugiyama, M. Shibata, S. Kajiura, T. Okuno, M. Tonari, H. Oku, et al., Invest. Ophthalmol. Vis. Sci. 52 (2011) 64-69.

[85] H. Watabe, S. Abe, T. Yoshitomi, Jpn. J. Ophthalmol. 55 (2011) 411-417.

[86] N. Sanjari, M. Pakravan, R. Nourinia, H. Esfandiari, A. Hafezi-Moghadam, S. Zandi, et al., J. Clin. Pharmacol. (2015) 1-5.

[87] S. Nakabayashi, M. Kawai, T. Yoshioka, Y. S. Song, T. Tani, A. Yoshida, et al., Exp. Eye Res. 139 (2015) 132-135.

[88] Z. Yang, J. Wang, X. Liu, Y. Cheng, L. Deng, Y. Zhong, Oncol. Rep. 29 (2013) 1140-1146.

[89] H. Sagawa, H. Terasaki, M. Nakamura, M. Ichikawa, T. Yata, Y. Tokita, et al., Exp. Neurol. 205 (2007) 230-240.

[90] M. Ichikawa, J. Yoshida, K. Saito, H. Sagawa, Y. Tokita, M. Watanabe, Brain Res. 1201 (2008) 23-33.

[91] J. Yu, L. Lin, X. Luan, X. Jing, 8 (2015) 14717-14724.

[92] A. M. Fontainhas, E. Townes-Anderson, Invest. Ophthalmol. Vis. Sci. 49 (2008) 4177-4187.

[93] K. Yamamoto, K. Maruyama, N. Himori, K. Omodaka, Y. Yokoyama, Y. Shiga, et al., Invest. Ophthalmol. Vis. Sci. 55 (2014) 7126-7136.

[94] A. M. Fontainhas, E. Townes-Anderson, Invest. Ophthalmol. Vis. Sci. 52 (2011) 579-587.

[95] P. A. Erickson, S. K. Fisher, D. H. Anderson, W. H. Stern, G. A. Borgula, Invest. Ophthalmol. Vis. Sci. 24 (1983) 927-942.

[96] S. K. Fisher, G. P. Lewis, Vision Res. 43 (2003) 887-897.

[97] A. M. Fontainhas, E. Townes-Anderson, Invest. Ophthalmol. Vis. Sci. 49 (2008) 4177-4187.

[98] W. Wang, E. Townes-Anderson, Invest. Ophthalmol. Vis. Sci. 56 (2015) 7847-7858.

[99] J. Wang, M. Zarbin, I. Sugino, I. Whitehead, E. Townes-Anderson, Invest. Ophthalmol. Vis. Sci. 57 (2016) 3892-3906.

[100] M. Li, Y. Huang, A. A. K. Ma, E. Lin, M. I. Diamond, Neurobiol. Dis. 36 (2009) 413-420. 
[101] M. Li, D. Yasumura, A. A. K. Ma, M. T. Matthes, H. Yang, G. Nielson, et al., PLoS One 8 (2013) 1-8.

[102] V. Gupta, N. Gupta, I. H. Shaik, R. Mehvar, I. F. McMurtry, M. Oka, et al., J. Control. Release 167 (2013) 189-199.

[103] K. Nahar, S. Absar, N. Gupta, V. R. Kotamraju, I. F. McMurtry, M. Oka, et al., Mol. Pharm. 11 (2014) 4374-4384.

[104] W. Wang, E. Townes-Anderson, Neural Regen. Res. 11 (2016) 1029-1032. 